\title{
Monocarboxylic Acids and Dicarboxylic Acids Induce Different Responses in terms of Osmotic Fragility in Rat and Guinea Pig Erythrocytes In vitro
}

Hitoshi Mineo*, Kazuki Kasai, Reo Makihara and Tomoya Yuuki

Department of Health and Nutrition, Faculty of Human Science, Hokkaido Bunkyo University, Eniwa, Hokkaido 061-1449, Japan

*Corresponding author: Hitoshi Mineo, Ph.D, Department of Health and Nutrition, Faculty of Human Science, Hokkaido Bunkyo University, Eniwa, Hokkaido 061-1449, Japan, Tel: 81-12-334-1635; E-mail: mineo@do-bunkyodai.ac.jp

Received date: Jul 22, 2016; Accepted date: Aug 17, 2016; Published date: Aug 24, 2016

Copyright: (C) 2016 Mineo $\mathrm{H}$, et al. This is an open-access article distributed under the terms of the Creative Commons Attribution License, which permits unrestricted use, distribution, and reproduction in any medium, provided the original author and source are credited.

\begin{abstract}
We compared the effects of monocarboxylic and dicarboxylic acids on osmotic fragility (OF) in rat and guinea pig red blood cells (RBCs) in vitro. Monocarboxylic acids possessing 4 to 8 straight-chain hydrocarbons increased OF in rat $\mathrm{RBCs}$ in a concentration-dependent manner. The increases in OF were also dependent on the number of carbons in the hydrocarbon chain bonded to the carboxylic group. Benzoic and cyclohexane-monocarboxylic acids also increased OF in rat RBCs in a dose-dependent manner. Although most of the dicarboxylic acids possessing a straight hydrocarbon chain decreased OF in rat RBCs, malonic acid showed the greatest potential to decrease OF among the substances tested. None of the monocarboxylic acids increased OF in guinea pig RBCs. Among the dicarboxylic acids possessing a benzene ring, isophthalic and terephthalic, but not phthalic acid, decreased OF in rat RBCs dose-dependently. Three cyclohexane-dicarboxylic acids decreased OF in guinea pig RBCs, while they had no effect on OF in rat RBCs. With regard to the action of those carboxylic acids on the cell membrane, hydrophobic hydrocarbons of a certain structure are thought to enter the phospholipid layer with the hydrophilic carboxylic group remaining at the membrane surface where it affects the nature of the cell membrane, thus changing osmotic resistance in the RBCs. Inter-species differences in the RBC membrane were confirmed in the OF response to those carboxylic acids. The differences in OF response to the monocarboxylic and dicarboxylic acids observed in rat and guinea pig RBCs are speculated to be due to differences in the nature of the RBC membrane formed by the various phospholipids.
\end{abstract}

Keywords: Carboxylic acid; Erythrocyte; Membrane; Osmotic fragility; Guinea pig; Rat; Inter-species differences; Phospholipid

\section{Introduction}

Previous reports have shown that osmotic fragility (OF) in erythrocytes is a useful indicator for evaluating the interactions between various substances and the cell membrane in vitro. It was demonstrated that general [1] and local anesthetics [2], some kinds of drugs [3] and toxins [4], as well as inorganic [5] and organic compounds [6] have the potential to change OF in red blood cells (RBCs). The cholesterol content, which is one of major components of the cell membrane, is known to affect membrane fragility in erythrocytes $[7,8]$. However, the mechanisms underlying these changes in $\mathrm{OF}$ in RBCs have not been clarified in detail.

We have demonstrated that the application of various kinds of monocarboxylic and dicarboxylic acids changes OF in isolated RBCs in rats in vitro [9]. Some monocarboxylic acids, possessing straight hydrocarbon chains of more than 4 carbon atoms in length, increase $\mathrm{OF}$ in both a dose-dependent and carbon atom number-dependent manner. Benzene-monocarboxylic acid (Benzoic acid) and some of its derivatives also increase OF in rat RBCs [10]. On the other hand, some dicarboxylic acids, including benzene dicarboxylic acids, decrease OF in rat RBCs [11]. A series of experiments indicated that monocarboxylic and dicarboxylic acids directly affect the cell membrane, particularly the phospholipid layer, and change its resistance to osmotic pressure in rat erythrocytes $[9,11]$.
In terms of their physico-chemical characteristics, both monocarboxylic and dicarboxylic acids are amphipathic substances, being composed of a hydrophobic hydrocarbon and one or two hydrophilic carboxylic groups. In terms of their direct effect on the RBC membrane, the hydrophobic hydrocarbon element is thought to enter the RBC membrane while the hydrophilic carboxylic groups remain outside, interacting with the phospholipids distributed on the outer surface of the cell membrane. Interactions between the hydrocarbon bound to the carboxylic group and phospholipids in the plasma membrane are thought to affect $\mathrm{RBC}$ resistance to osmotic pressure.

We have used rat RBCs as a prototypical cellular model system to examine chemical-mediated effects on the plasma membrane. However, there have been many reports that the composition of phospholipids in erythrocytes appear to differ among species [12-15]. It is, therefore, now unclear whether the effects of monocarboxylic acids and/or dicarboxylic acids on OF are a particular phenomenon in rat erythrocytes or represent a common characteristic in erythrocytes across animal species.

Thus, we compared the OF response to some monocarboxylic and dicarboxylic acids in RBCs isolated from rats and guinea pigs whether the OF response to various carboxylic acids reported in rat RBCs was similar to that in guinea pig RBCs and gain better further insight into the problem of inter-species differences. 


\section{Materials and Methods}

\section{Animals}

The animals were maintained in accordance with the National Institutes of Health Guidelines for the Care and Use of Laboratory Animals. The feeding of animals and sampling of blood were performed at the Institute of Experimental Animals in the New Drug Research Center, Inc. (Eniwa, Hokkaido, Japan).

Male Sprague-Dawley rats (Crl:CD (SD), 8 weeks old, Charles River Laboratories Japan, Inc., Japan) and male Hartley guinea pigs (Slc:Hartley, 4 weeks old, Japan SLC, Shizuoka, Japan) were housed in individual stainless-steel metabolic cages. The cages were placed in a room with controlled temperature $\left(22 \pm 3^{\circ} \mathrm{C}\right)$, relative humidity $(50 \pm$ $20 \%$ ) and lighting (light 08:00-20:00). The animals had free access to tap water and a pelleted rat (CRF-1, Oriental yeast Co., Ltd., Tokyo, Japan) or guinea pig diet (Labo G standard, Nosan Co., Yokohama, Japan) for more than 1 week before the start of the experiments. Blood samples were collected from the rats $(387 \pm 31 \mathrm{~g}, \mathrm{n}=8)$ and guinea pigs ( $415 \pm 74 \mathrm{~g}, \mathrm{n}=12$ ) from 9 to 12 ( $10 \pm 1$ weeks) and 5 to 7 weeks old (6 \pm 1 weeks), respectively.

\section{Reagents}

Biochemical grade formic acid, acetic acid, propionic acid, n-butyric acid, n-valeric acid, n-caproic acid, n-enathic acid, n-capric acid, oxalic acid, malonic acid, succinic acid, glutaric acid, adipic acid, pimelic acid, suberic acid, azelaic acid, benzene-monocarboxylic acid (benzoic acid), 1, 2-benzenedicarboxylic acid (phthalic acid), 1, 3benzenedicarboxylic acid (isophthalic acid), 1, 4-benzenedicarboxylic acid (terephthalic acid), cyclohexane-monocarboxylic acid, and 1,2-, 1, 3-, and 1, 4-cyclohexane-dicarboxylic acids (cis- and trans-mixture) were purchased from Tokyo Kasei Kogyo Co., Ltd (Tokyo, Japan) or Wako Pure chemical Co., Ltd. (Osaka, Japan). All other reagents used in this study were of biochemical grade.

All patients with medical conditions were first managed by the specialist to treat the primary causes and all patients were evaluated post operatively regarding to: discharge destination, mortality, morbidity, pain status and daily activity.

\section{Preparation of rat and guinea pig RBCs}

On the day of the experiment, the rats and guinea pigs were anesthetized with pentobarbital sodium $(60 \mathrm{mg} / \mathrm{kg})$. Blood samples $(12-15 \mathrm{ml})$ were collected into heparinized test tubes from the abdominal aorta in rats and the postcava in guinea pigs. The RBCs were separated from the plasma by centrifugation at $2000 \mathrm{~g}$ for $15 \mathrm{~min}$ (Model 2420, Kubota Inc., Tokyo, Japan). The crude RBCs obtained were then washed three times with cold $0.9 \% \mathrm{NaCl}$ solution at two times the volume of RBCs. A dense-packed cell suspension was obtained and thereafter kept in ice-cold water until subsequent treatment.

\section{Experimental Procedure}

The experimental procedures were similar to those reported previously $[10,11]$. The dense-packed cell suspension $(30 \mu \mathrm{l})$ was transferred into a $0.6 \mathrm{ml}$ of phosphate- $\mathrm{NaCl}$ buffer solution $(\mathrm{pH} 7.4)$ containing monocarboxylic or dicarboxylic acids at $0,0.1,0.25,0.5,1$, $2.5,5,10,25,50$ and $100 \mathrm{mM}$ in $1.5-\mathrm{ml}$ micro test tubes (Nichiryo Co., Ltd., Tokyo, Japan). The osmolarity was regulated by the amount of
$\mathrm{NaCl}$ added to the buffer solution when each substance was applied. To compare the effect of each monocarboxylic acid (parent chemical) and its corresponding dicarboxylic acid, OF determination was undertaken using RBCs obtained from the same animal. All RBC suspensions used for treatment with the chemical compounds were incubated by shaking (1 stroke/sec) at $37^{\circ} \mathrm{C}$ for $1 \mathrm{hr}$ (Shaking Bath TBK $202 \mathrm{DA}$. Advantec Co., Ltd., Tokyo, Japan). Each RBC suspension was mixed gently by mixer (Vortex Genie 2, model-G560, Scientific Industry, Inc. NY., USA) after incubation, and then $50 \mu$ aliquots were transferred into a 96 deep-well micro-plate ( $2 \mathrm{ml}$ volume, Whatman Inc., Piscataway, NJ, USA) containing $1 \mathrm{ml}$ of $\mathrm{NaCl}$ solution ranging from 0.1 to $0.8 \%$. The deep well plate was immediately centrifuged at $1300 \mathrm{~g}$ (Plate Spin II, Kubota Inc., Tokyo, Japan) for $10 \mathrm{~min}$ at room temperature. The supernatants $(200 \mu \mathrm{l})$ containing various concentrations of hemoglobin derived from the hemolyzed RBCs were transferred into another 96 well micro-plate $(300 \mu \mathrm{l}$ volume, Whatman Inc., Piscataway, NJ, USA) and determined colorimetrically at $540 \mathrm{~nm}$ (Microplate Reader Model 680, Bio-Rad Laboratories, Tokyo, Japan).

\section{Statistical Analysis}

Complete hemolysis of the RBC suspension occurred in the $0.1 \%$ $\mathrm{NaCl}$ solution, for which the hemoglobin concentration was defined as $100 \%$. Hemolysis of the RBCs did not occur in the $0.8 \% \mathrm{NaCl}$ solution, for which the hemoglobin concentration was defined as $0 \%$. The effective concentration of the $\mathrm{NaCl}$ solution inducing $50 \%$ hemolysis (EC50) of the applied RBCs was calculated from the hemolysis curve by using a straight-line equation between the points immediately adjacent to $50 \%$. The EC50 value was used to indicate OF in the erythrocytes. All values are expressed as means \pm S.D. The significance of the differences between the control $(0 \mathrm{mM})$ and subsequent concentrations (0.1-100 mM) was determined by Dunnett's test following one-way ANOVA. Statistical analyses were performed using Excel Tokei for Windows 2012 (SSRI Co., Ltd., Tokyo, Japan). A difference with $\mathrm{P}<0.05$ was considered to be statistically significant.

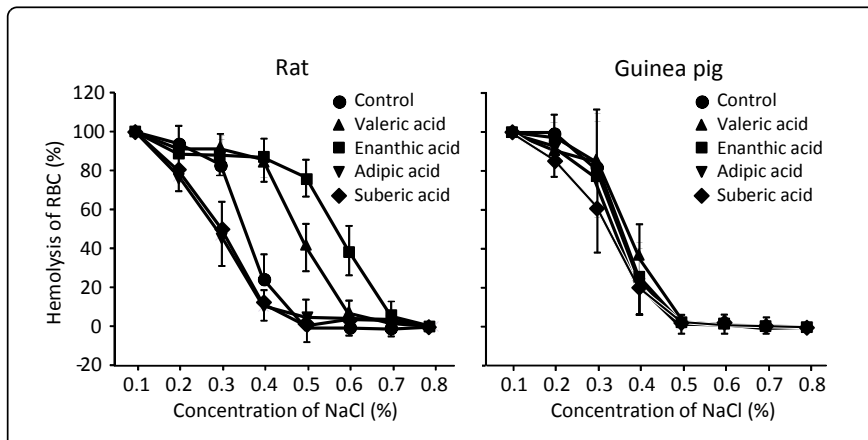

Figure 1: Typical hemolytic curves for rat and guinea pig RBCs exposed to monocarboxylic and dicarboxylic acids. Data for rats (left panel) and guinea pigs (right panel) are shown. Values are means $\pm S D(n=6)$. Hemolytic curves for rat and guinea pig RBCs were obtained after exposure to substances at each concentration for $1 \mathrm{hr}$. Curves were determined for the control (no tested substance) at $0 \mathrm{mM}$, and $\mathrm{n}$-valeric, $\mathrm{n}$-enathic, adipic and suberic acid at $100 \mathrm{mM}$ (other concentrations not shown). The EC50 values for hemolysis (concentration in $\mathrm{NaCl} \%$ ) were obtained using a straight-line equation between the points immediately above and below $50 \%$. The values obtained were used as a measure of OF. 
Citation: Mineo H, Kasai K, Makihara R, Yuuki T (2016) Monocarboxylic Acids and Dicarboxylic Acids Induce Different Responses in terms of Osmotic Fragility in Rat and Guinea Pig Erythrocytes In vitro. J Membra Sci Technol 6: 156. doi:10.4172/2155-9589.1000156

Page 3 of 7

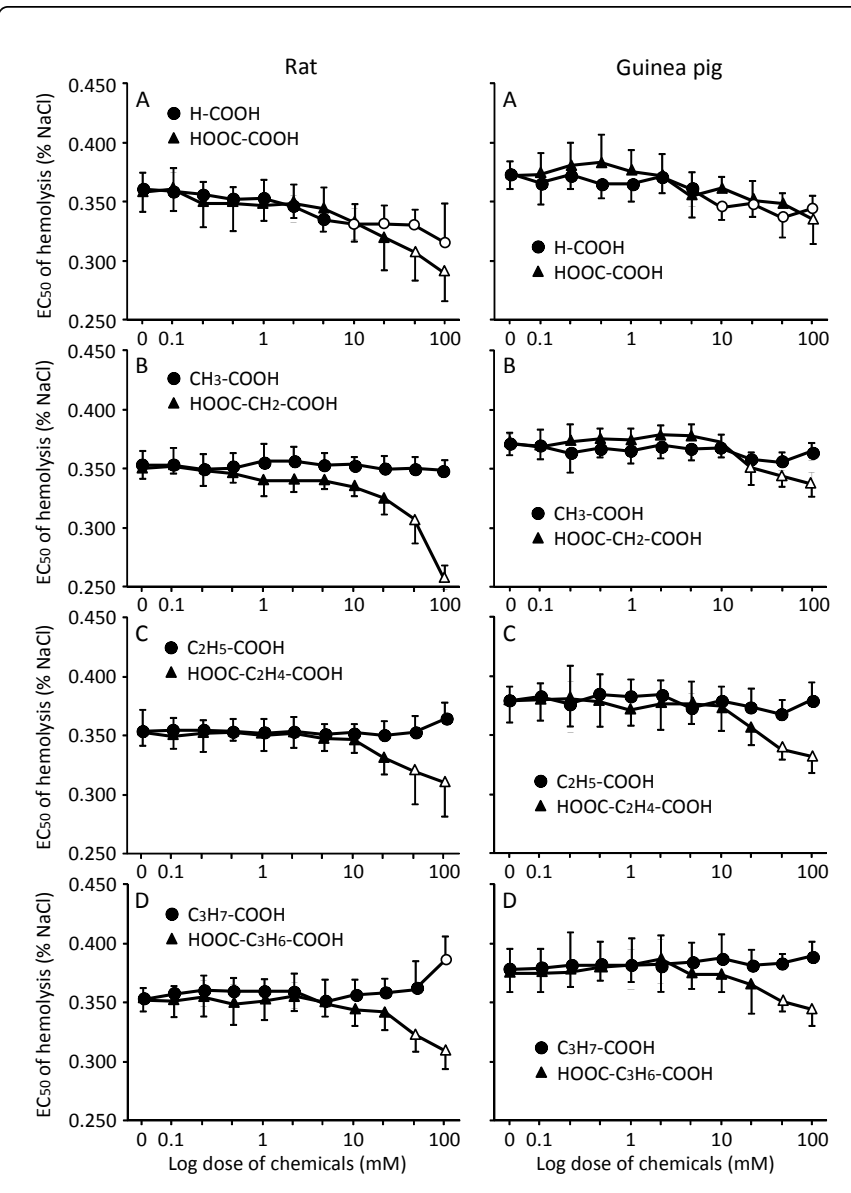

Figure 2: Effects of monocarboxylic acids with straight hydrocarbon chains and their corresponding dicarboxylic acids on $\mathrm{OF}$ in rat and guinea pig RBCs. Data for rats (left panel) and guinea pigs (right panel) are shown. Comparisons between the effects of formic and oxalic acid (A), acetic and malonic acid (B), propionic and succinic acid (C), and n-butyric and glutaric acid (D) are presented. Values are the means $\pm \mathrm{SD}(\mathrm{n}=6)$. The monocarboxylic acid is represented by closed circles $(\bullet)$ and the dicarboxylic acid by closed triangles $(\boldsymbol{\Delta})$. Open symbols indicate that there was a significant difference between the control $(0 \mathrm{mM})$ and subsequent concentrations $(0.1-100 \mathrm{mM})$ on the basis of Dunnett's test $(\mathrm{P}<0.05)$.

\section{Results}

\section{Typical hemolytic curves for rat and guinea pig RBCs in} response to monocarboxylic and dicarboxylic acids

Typical hemolytic curves for rat and guinea pig RBCs exposed to monocarboxylic and dicarboxylic acids are shown in Figure 1. The 50\% hemolysis of the added RBCs was defined as the EC50 value and used as a measure of OF. The EC50 value in rat RBCs was $0.357 \pm 0.018$ for the control at $0 \mathrm{mM}, 0.483 \pm 0.030$ for $n$-valeric acid at $100 \mathrm{mM}, 0.580$ \pm 0.043 for $\mathrm{n}$-enathic acid at $100 \mathrm{mM}, 0.308 \pm 0.045$ for adipic acid at $100 \mathrm{mM}$ and $0.312 \pm 0.024$ for suberic acid. The curves were shifted to be right with increases in monocarboxylic acid concentration and were shifted slightly to be left with increases in dicarboxylic acid concentration. On the other hand, in guinea pig RBCs, the EC50 value was $0.379 \pm 0.018$ (control at $0 \mathrm{mM}), 0.393 \pm 0.015$ (n-valeric acid at $100 \mathrm{mM}$ ), $0.345 \pm 0.022$ (n-enathic acid at $100 \mathrm{mM}$ ), $0.357 \pm 0.013$ (adipic acid at $100 \mathrm{mM}$ ) and $0.343 \pm 0.007$ (suberic acid at $100 \mathrm{mM}$ ). The curves were not changed by treatment with monocarboxylic acid and were slightly shifted to the left by treatment with dicarboxylic acid in a concentration-dependent manner.

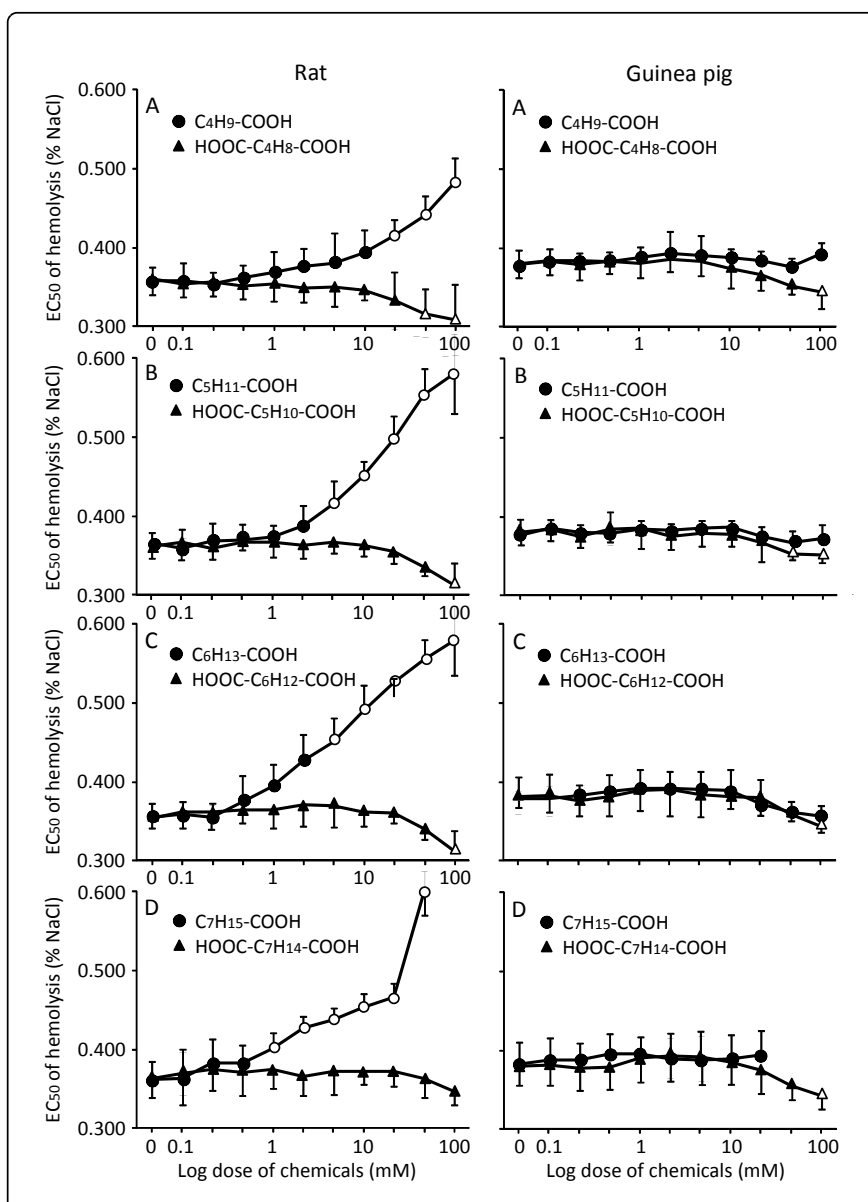

Figure 3: Effects of monocarboxylic acids with straight hydrocarbon chains and their corresponding dicarboxylic acids on $\mathrm{OF}$ in rat and guinea pig RBCs. Data for rats (left panel) and guinea pigs (right panel) data are shown. Comparisons between the effects of $n$-valeric and adipic acid (A), n-caproic and pimelic acid (B), n-enathic and suberic acid (C), and n-capric and azelaic acid (D) are presented. Values are the means \pm SD $(n=6)$. The monocarboxylic acid is represented by closed circles $(\bullet)$ and the dicarboxylic acid by closed triangles $(\boldsymbol{\Delta})$. Open symbols indicate that there was a significant difference between the control $\left(\begin{array}{lll}0 & \mathrm{mM}\end{array}\right)$ and subsequent concentrations $(0.1-100 \mathrm{mM})$ on the basis of Dunnett's test $(\mathrm{P}<0.05)$.

\section{The effects of monocarboxylic and dicarboxylic acids possessing straight hydrocarbon chains on OF in rat and guinea pig RBCs}

Concentration-response relationships between the tested chemicals and their effects on the EC50 values in rat and guinea pig RBCs are shown in Figures 2 and 3. 
The application of monocarboxylic acids, except for formic, acetic and propionic acids, increased $\mathrm{OF}$ in the rat RBCs in a concentrationdependent manner $(\mathrm{P}<0.05)$. The increases in $\mathrm{OF}$ were also dependent on the number of carbon atoms in the respective hydrocarbon chains. No OF value could be obtained for $\mathrm{n}$-capric acid at $100 \mathrm{mM}$ as hemolysis of the RBCs occurred immediately on its application at that concentration (Figure 3D). For dicarboxylic acids, most of the acids tested, except azelaic acid, decreased $\mathrm{OF}$ in a concentration-dependent manner in rat RBCs. The decrease in OF induced by malonic acid was the largest among the dicarboxylic acids tested (Figure 2B). Statistically significant decreases in OF occurred at a dicarboxylic acid concentration of 50 and/or $100 \mathrm{mM}(\mathrm{P}<0.05)$. Azelaic acid tended to decrease OF, but no significant decrease in OF was obtained even at $100 \mathrm{mM}$ (Figure 3D).

Except for formic acid and n-capric acid, the treatment of guinea pig RBCs with monocarboxylic acids did not change the OF (Figures 2 and 3). Formic acid gradually decreased $O F$ with increases in concentration with statistically significant decreases $(\mathrm{P}<0.05)$ obtained at concentrations of $10 \mathrm{mM}$ or more (Figure $2 \mathrm{~A}$ ). Although no change in $\mathrm{OF}$ was observed on treatment with n-capric acid up to $25 \mathrm{mM}$, hemolysis of the RBCs occurred abruptly at concentrations of 50 and $100 \mathrm{mM}$. Thus, no OF value could be obtained for n-capric acid at 50 or $100 \mathrm{mM}$ in guinea pig RBCs (Figure 3D). All of the tested dicarboxylic acids decreased $\mathrm{OF}$ in guinea pig RBCs in a concentration-dependent manner (Figures 2 and 3). Statistically significant decreases in $\mathrm{OF}$ were observed at dicarboxylic acid concentrations of 25, 50 and/or $100 \mathrm{mM}(\mathrm{P}<0.05)$.

\section{The effects of monocarboxylic and dicarboxylic acids possessing ring-like hydrocarbons on $O F$ in rat and guinea pig RBCs.}

The application of benzoic acid increased OF in rat RBCs, with OF values significantly higher than the control value $(0 \mathrm{mM})$ observed at concentrations above $25 \mathrm{mM}(\mathrm{P}<0.05)$ (Figure $4 \mathrm{~A})$. Although phthalic acid treatment did not affect $\mathrm{OF}$ in rat RBCs, isophthalic and terephthalic acids both decreased OF in a dose-dependent manner. OF values significantly lower than the control value $(0 \mathrm{mM})$ were induced at 50 and $100 \mathrm{mM}(\mathrm{P}<0.05)$. In guinea pig RBCs, the application of benzoic acid, phthalic and terephthalic acids decreased OF, with the values obtained at $100 \mathrm{mM}$ being significantly lower than the control value $(\mathrm{P}<0.05)$ (Figure $4 \mathrm{~A})$. Isophthalic acid tended to decrease $\mathrm{OF}$, but the change was not statistically significant.

For compounds possessing a cyclohexane ring, cyclohexanemonocarboxylic acid increased $\mathrm{OF}$ in rat RBCs in a dose-dependent manner, with the values obtained at $10 \mathrm{mM}$ or more being significantly higher than the control value $(\mathrm{P}<0.05)$ (Figure $4 \mathrm{~B})$. The three kinds of cyclohexane-dicarboxylic acid tested did not affect $\mathrm{OF}$ in rat RBCs at any of the concentrations tested. In guinea pig RBCs, cyclohexanemonocarboxylic acid and the three tested cyclohexane-dicarboxylic acids decreased OF, with the values obtained at 50 and/or $100 \mathrm{mM}$ being significantly lower than the control value $(\mathrm{P}<0.05)$ (Figure $4 \mathrm{~B})$.

\section{Discussion}

The results of this study showed that OF responses to monocarboxylic acids and dicarboxylic acids vary considerably between rat and guinea pig erythrocytes. Most of the monocarboxylic acids tested, except for those possessing a short, straight hydrocarbon chain, demonstrated OF-increasing activity in rat RBCs. However, none of the monocarboxylic acids tested in the present experiment showed OF-increasing activity in guinea pig RBCs. With regard to the dicarboxylic acids, most of those tested demonstrated OF-decreasing activity in both rat and guinea pig erythrocytes. Although hemolysis was induced by n-capric acid at 50 and/or $100 \mathrm{mM}$ in both rat and guinea pig RBCs, dose-dependent increases in OF were also induced at lower doses below $50 \mathrm{mM}$ in rat, but not in guinea pig RBCs. This is the first report to compare OF responses to monocarboxylic and dicarboxylic acids in erythrocytes from different animal species.

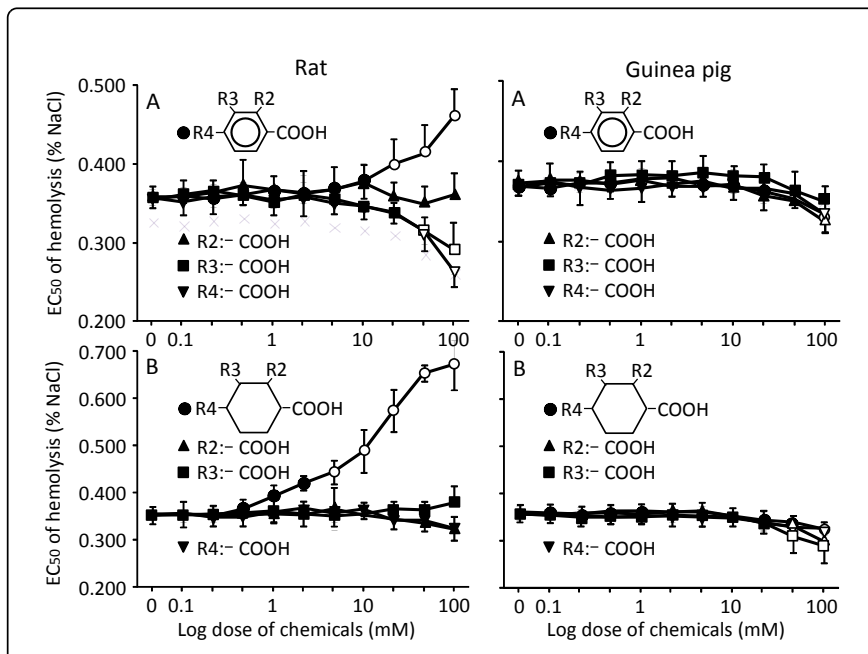

Figure 4: Effects of benzene monocarboxylic acids, cyclohexane monocarboxylic acid and their corresponding dicarboxylic acids on OF in rat and guinea pig RBCs. Data for rats (left panel) and guinea pigs (right panel) data are shown. Comparisons between the effects of benzene-monocarboxylic acid and three kinds of benzenedicarboxylic acid (A), or cyclohexane-monocarboxylic acid and three kinds of cyclohexane-dicarboxylic acid (B) are presented. Values are the means \pm SD $(n=6)$. Benzoic acid, phthalic acid, isophthalic acid and terephthalic acid are represented by closed circles $(\bullet)$, closed triangles $(\boldsymbol{\Delta})$, closed squares $(\bullet)$, and closed inverted triangles $(\boldsymbol{\nabla})$, respectively, in panel $A$; and cyclohexanemonocarboxylic acid, 1,2-, 1,3-, and 1,4-cyclohexane-dicarboxylic acid are presented by closed circles $(\bullet)$, closed triangles $(\boldsymbol{\Delta})$, closed squares ( $\mathbf{\bullet}$ ), closed inverted triangles $(\boldsymbol{\nabla})$, respectively, in panel B. Open symbols indicate that there was a significant difference between the control $(0 \mathrm{mM})$ and subsequent concentrations $(0.1-100 \mathrm{mM})$ on the basis of Dunnett's test $(\mathrm{P}<0.05)$.

There have been many reports that monocarboxylic acids directly affect the phospholipid bilayer of the plasma membrane to induce biological activities in specific tissues or cells. Monocarboxylic acids, including benzoic acid, and its chemical analogues, affect the axonal membrane to accelerate procaine absorption into the lipid bilayer both in vivo and in vitro $[16,17]$. n-Butyric acid changes the fluidity of the cell membrane of colon cancer cells [18], while salicylic acid derivatives, which are also derivatives of benzoic acid, affect the plasma membrane and change the shape, stiffness and relaxation time of isolated RBCs [19]. Based on X-ray diffraction and fluorescence spectroscopy studies, it has recently been reported that acetylsalicylic acid and salicylic acid interact with human erythrocytes and perturb the membrane bilayer [20]. These results suggest that both the carboxylic acids investigated in this study might also change the 
structure and strength of the cell membrane, thereby inducing biological activity in individual cells.

Based on the same experimental techniques as those used in the present study, we previously reported, that some monocarboxylic acids increase OF, whereas their corresponding dicarboxylic acids decrease $\mathrm{OF}$ in rat RBCs [11]. We hypothesized that monocarboxylic and dicarboxylic acids also interact with the lipid bilayer of the RBC membrane, resulting in the observed changes in $\mathrm{OF}$ in rat erythrocytes. Both types of carboxylic acid possessed a hydrophobic hydrocarbon element and one or two hydrophilic carboxylic groups in their molecules. We speculated that the hydrocarbon chain enters the RBC membrane, with the hydrophilic carboxylic base remaining outside of the membrane, where it interacts with the phospholipids present in the outer layer of the plasma membrane $[9,11]$. The degree of activity on the cell membrane probably depends on the dimensions (length, size and/or form) of the hydrophobic hydrocarbon chain in the molecules. On the other hand, the composition of the phospholipids in the cell membrane was reported to vary between tissues within the same species [21] and between the same tissues among different species [22]. The biological activities of carboxylic acids may, therefore, be dependent not only on their chemical structure but also on the characteristics of the lipid layer in which the action sites are located.

Although the composition of the compounds contained in the cell membrane is complicated, apart from proteins, the cell membrane layer is mostly composed of two lipid-soluble substances, cholesterol and phospholipid. We have calculated the cholesterol/total lipid (cholesterol plus phospholipid) ratio in guinea pig and rat erythrocytes from the data presented in two previous reports $[12,13]$. The values obtained were 0.73 and 0.42 for rats and 0.53 and 0.34 for guinea pigs, respectively, with the ratio of cholesterol in guinea pig RBCs slightly lower than that in rat RBCs. It was demonstrated that the cholesterol content in the membrane affects osmotic resistance in erythrocytes or, more accurately, the cholesterol:phospholipid ratio was shown to be inverse proportion to OF in human RBCs $[23,24]$.

\begin{tabular}{|c|c|c|c|c|}
\hline \multirow{2}{*}{$\begin{array}{l}\text { Phospholipid head and fluidity } \\
\text { index }\end{array}$} & \multicolumn{2}{|r|}{ A } & \multicolumn{2}{|r|}{ B } \\
\hline & Rat & Guinea pig & Rat & Guinea pig \\
\hline Phosphatidyl choline (PC) & 47.1 & 41.1 & 48.1 & 50.9 \\
\hline Phosphatidyl ethanolamine (PE) & 21.5 & 24.6 & 23 & 21.8 \\
\hline Phosphatidyl serine (PS) & 10.8 & 16.8 & 9.4 & 11.3 \\
\hline Phosphatidyl inositol (PI) & 3.5 & 2.4 & 4.5 & 2 \\
\hline Sphingomyelin (SM) & 12.8 & 11.1 & 13.3 & 11.6 \\
\hline Phosphatidic acid (PA) & $>0.3$ & 4.2 & 0 & 2.7 \\
\hline Lysophospadidyl choline (LC) & 3.8 & $>0.3$ & 1.3 & 0 \\
\hline Phospholipid fluidity index & 1.4 & 1.2 & 1.3 & 1.5 \\
\hline \multicolumn{5}{|c|}{$\begin{array}{l}\text { Values are the percentage of total phospholipids in the RBC membrane. The } \\
\text { values are quoted from A [13] and B [14]. The phospholipid fluidity index was } \\
\text { calculated from the respective phospholipid values using the formula (PC/(PE } \\
+ \text { SM)) [25]. }\end{array}$} \\
\hline
\end{tabular}

Table 1: Essential phospholipid composition and phospholipid fluidity index in rat and guinea pig RBCs.
There are some reports on the ratio of hydrophilic head-type phospholipids in the rat and guinea pig RBC membranes $[13,14]$. The percentages of each head type among the phospholipids in rat and guinea pig RBCs are shown in Table 1 . The ratio of each head type among phospholipids in the membranes differs slightly between rat and guinea pig RBCs. With regard to the phospholipid fluidity index as a determinant of cell membrane fluidity [25], however, there is no apparent difference between the rat and guinea pig RBCs (Table 1).

Hydrophobic acyl hydrocarbons are derived from fatty acids, which include acyl chains of various lengths, and have both saturated and unsaturated carbon bonds in the moiety. We found the ratios of the main fatty acids in rat and guinea pig erythrocytes from data in two different reports $[12,26]$ (Table 2). Another report compared the fatty acid composition in rat and guinea pig RBCs [15] (Table 2). Remarkable variations can be seen in the composition of fatty acids bound to the hydrophilic head of phospholipids in rat and guinea pig RBCs. The saturation index, a determinant of cell membrane fluidity [27], was lower in rat RBCs than in guinea pig RBCs. These results indicate that membrane fluidity in rat RBCs is higher than that in guineas pig RBCs. In a previous experiment using specific phosphatidylcholine (PC) transfer protein, total replacement of native PC with 1-palmitoil-2-oleoyl and 1-palmitoil-2-linoleoyl PC in the outer layer of the human erythrocyte did not change $\mathrm{OF}$ values or potassium ion $(\mathrm{K}+)$ permeability [28]. On the other hand, 1palmitoil-2-alachidonoyl PC in human RBCs induces $\mathrm{K}+$ leakage from cells [28]. Polyunsaturated fatty acids, including alachidonic acid, have a crooked acyl chain in their moiety. These chains are thought to disturb the rigid binding of acyl-chains in the phospholipid layer of the cell membrane. This disturbance of the membrane structure subsequently facilitates interactions between the carboxylic acid and the membrane. Differences in fatty acid composition between erythrocyte membranes is speculated to be one of the factors explaining the differences in OF response between rat and guinea pig RBCs. The notion that OF in rat RBCs is influenced by the distribution of the different types of fatty acids is supported by the results of previous reports $[29,30]$.

\begin{tabular}{|l|c|c|c|c|c|}
\hline \multirow{2}{*}{$\begin{array}{l}\text { Fatty acid and } \\
\text { saturation index }\end{array}$} & \multicolumn{2}{|c|}{ A } & \multicolumn{2}{|c|}{ B } & \multicolumn{2}{c|}{ C } \\
\cline { 3 - 6 } & & Rat & Guinea pig & Rat & Guinea pig \\
\hline Saturated fatty acid & & & & & \\
\hline Palmitic acid & $(16: 0)$ & 26.9 & 11.2 & 22.1 & 12 \\
\hline Stearic acid & $(18: 0)$ & 15.9 & 27.1 & 14.8 & 24.9 \\
\hline Unsaturated fatty acid & & & & & \\
\hline Oleic acid & $(18: 1)$ & 5.5 & 7.1 & 8.9 & 9.9 \\
\hline Linoleic acid & $(18: 2)$ & 10.5 & 19.5 & 11.4 & 19.9 \\
\hline Arachidonic acid & $(20: 4)$ & 36.2 & 23.2 & 30.0 & 18.0 \\
\hline Saturation index & & 2.9 & 3.8 & 1.7 & 2.5 \\
\hline Varly & & & & \\
\hline
\end{tabular}

Values are the percentage of total phospholipids in the RBC membrane. The values are quoted from A [26], B [12] and C [15]. The saturation index was calculated from the respective fatty acid values using the formula (Stearic acid/ Oleic acid) [27]

Table 2: Essential fatty acid composition and saturation index in rat and guinea pig RBCs. 
The composition of phospholipids in the RBC membrane, however, is much more complicated. It was reported that the membrane lipid bilayer in erythrocytes is asymmetrical, or that the type and amount of phospholipids differ between the outer and inner layers of the RBC membrane in humans [31] and other animals [32-35]. The distribution of phospholipids in the outer and inner leaflet has been compared and demonstrated to differ markedly among various mammalian species [36]. It has also been demonstrated that the type and amount of acyl chain-bonded hydrophilic heads differ between the outer and inner layer of the RBC membrane in various species [32,33,37]. At present, information is available for the phospholipid composition in rat $\mathrm{RBCs}$ [32], but not in guinea pig RBCs.

In terms of the direct action of carboxylic acids, after the hydrophobic portion enters the cell membrane, interaction between these elements and phospholipids in the cell membrane are thought to occur under various conditions, resulting in changes in the membrane matrix characteristics. Therefore, the differences in OF response observed on the application of the same compound, as observed in rat and guinea pig erythrocytes, is thought to be related to the composition of the cell membrane, particularly the outer phospholipid layer, not the tested compound itself.

In conclusion, we clarified that OF response to monocarboxylic and dicarboxylic acids differs between rat and guinea pig RBCs. The biological activities of various carboxylic acids thought to be dependent not only on their chemical structure but also on the characteristics of the lipid layer. The phospholipid composition of the cell membrane was reported to vary between tissues within the same species [21] and between the same tissues among different species [22]. We, therefore, need to clarify whether the phenomenon observed in this study can be extrapolated to the erythrocytes of species other than rats and guinea pigs.

\section{Acknowledgement}

We wish to thank Toyomasa Ashino and his staff at the Institute of Experimental Animals in the New Drug Research Center, Inc., for technical assistance.

\section{References}

1. Oker K, Ozer NK (1990) Effect of chronic halothane exposure on lipid peroxidation, osmotic fragility and morphology of rat erythrocytes. Appl Toxicol 10: 407-409.

2. Bazzoni G, Rasia M (2001) Effect of tetracaine chlorhydrate on the mechanical properties of the erythrocyte membrane. Blood Cells Mol Dis 27: 391-398.

3. Silva MMC, Madeira VM, Almeida LM, Custãdio JB (2001) Hydroxytamoxifen interaction with human erythrocyte membrane and induction of permeabilization and subsequent hemolysis. Toxicol In Vitro 15: 615-622.

4. Cusinato DA, Souza AM, Vasconcelos F, Guimarães LF, Leite FP, et al. (2010) Assessment of biochemical and hematological parameters in rats injected with Tityus serrulatus scorpion venom. Toxicon 56: 1477-1486.

5. Abad C, Carrasco MJ, Piaero S, Delgado E, Chiarello DI, et al. (2010) Effect of magnesium sulfate on the osmotic fragility and lipid peroxidation of intact red blood cells from pregnant women with severe preeclampsia. Pregnancy Hypertens 29: 38-53.

6. Quan GB, Han Y, Liu MX, Fang L, Du W, et al. (2011) Addition of oligosaccharide decreases the freezing lesions on human red blood cell membrane in the presence of dextran and glucose. Cryobiology 62: 135-144.
7. Dumas D, Didelon J, Humbert JC, Gigout T, Rasia RJ, et al. (1996) Effect of cholesterol on the cellular deformability and osmotic fragility of erythrocytes. J Mal Vasc 21: 181-184.

8. Kempaiah RK, Srinivasan K (2002) Integrity of erythrocytes of hypercholesterolemic rats during spices treatment. Mol Cell Biochem 236: $155-161$.

9. Mineo H, Hara H (2007) Chemical specificity in short-chain fatty acids and their analogues in increasing osmotic fragility in rat erythrocytes in vitro. Biochim Biophys Acta 1768: 1448-1453.

10. Mineo H, Ogita A, Kanayama N, Kawagishi M, Sato E, et al. (2013) Effect of the chemical specificity of benzoic acid and its analogs on osmotic fragility in erythrocytes of Sprague-Dawley rats in vitro. Eur J Pharmacol 702: 142-148.

11. Mineo H, Amita N, Kawawake M, Higuchi A (2013) Dicarboxylic acids with limited numbers of hydrocarbons stabilize cell membrane and increase osmotic resistance in rat erythrocytes. Biochim Biophys Acta 1828: 2379-2384.

12. Ostwald R, Shannon A (1964) Composition of tissue lipids and anaemia of guinea pigs in response to dietary cholesterol. Biochem J 91: 146-154.

13. Nelson GJ (1967) Lipid composition of erythrocytes in various mammalian species. Biochim Biophys Acta 144: 221-232.

14. Diagne A, Fauvel J, Record M, Chap H, Douste-Blazy L (1984) Studies on ether phospholipids. II. Comparative composition of various tissues from human, rat and guinea pig. Biochim Biophys Acta 793: 221-231.

15. Horrobin DF, Huang YS, Cunnane SC, Manku MS (1984) Essential fatty acids in plasma, red blood cells and liver phospholipids in common laboratory animals as compared to humans. Lipids 19: 806-811.

16. Hiji Y, Miyoshi M, Ichikawa O, Kasagi T, Imoto T (1987) Enhancement of local anaesthesia action by organic acid salts. (I): Possible change of excitability in nerve fibre membrane. Arch Int Physiol Biochem 95: 113-120.

17. Ichikawa O (1987) Enhancement of local anaesthesia action by organic acid salts. (II): Aspect of kinetics in the claw nerve membrane of crayfish. Arch Int Physiol Biochim 95: 121-131.

18. Dibner MD, Ireland KA, Koerner LA, Dexter DL (1985) Polar solventinduced changes in membrane lipid lateral diffusion in human colon cancer cells. Cancer Res 45: 4998-5003.

19. Li A, Seipelt H, Müller C, Shi Y, Artmann M (1999) Effects of salicylic acid derivatives on red blood cell membranes. Pharmacol Toxicol 85: 206-211.

20. Suwalsky M, Belmar J, Villena F, Gallardo MJ, Jemiola-Rzeminska M, et al. (2013) Acetylsalicylic acid (aspirin) and salicylic acid interaction with the human erythrocyte membrane bilayer induce in vitro changes in the morphology of erythrocytes. Arch Biochem Biophys 539: 9-19.

21. Di Marino L, Maffettone A, Cipriano P, Sacco M, Di Palma R, et al. (2000) Is the erythrocyte membrane fatty acid composition a valid index of skeletal muscle membrane fatty acid composition? Metabolism 49: 1164-1166.

22. Wessels JM, Veerkamp JH (1973) Some aspects of the osmotic lysis of erythrocytes. 3. Comparison of glycerol permeability and lipid composition of red blood cell membranes from eight mammalian species. Biochim Biophys Acta 291: 190-196.

23. Cooper RA, Arner EC, Wiley JS, Shattil SJ (1975) Modification of red cell membrane structure by cholesterol-rich lipid dispersions. A model for the primary spur cell defect. J Clin Invest 55: 115-126.

24. Suda T, Maeda N, Shiga T (1980) Effect of cholesterol on human erythrocyte membrane. A spin label study. J Biochem 87: 1703-1713.

25. Fajardo VA, McMeekin L, LeBlanc PJ (2011) Influence of phospholipid species on membrane fluidity: a meta-analysis for a novel phospholipid fluidity index. J Membr Biol 244: 97-103.

26. Watanabe N, Onuma K, Fujimoto K, Miyake S, Nakamura T (2011) Long-term effect of an enteral diet with a different n-6/n-3 ratio on fatty acid composition and blood parameters in rats. J Oleo Sci 60: 109-115. 
Citation: Mineo H, Kasai K, Makihara R, Yuuki T (2016) Monocarboxylic Acids and Dicarboxylic Acids Induce Different Responses in terms of Osmotic Fragility in Rat and Guinea Pig Erythrocytes In vitro. J Membra Sci Technol 6: 156. doi:10.4172/2155-9589.1000156

Page 7 of 7

27. Pala V, Krogh V, Muti P, Chajès V, Riboli E, et al. (2001) Erythrocyte membrane fatty acids and subsequent breast cancer: a prospective Italian study. J Natl Cancer Inst 93: 1088-1095.

28. Kuypers FA, Roelofsen B, Op den Kamp JA, Van Deenen LL (1984) The membrane of intact human erythrocytes tolerates only limited changes in the fatty acid composition of its phosphatidylcholine. Biochim Biophys Acta 769: 337-347.

29. Benga G, Travis BD, Pop VI, Popescu O, Toader S, et al. (1984) The effect of the saturation and isomerization of dietary fatty acids on the osmotic fragility and water diffusional permeability of rat erythrocytes. Biochim Biophys Acta 775: 255-259.

30. Hagve TA, Johansen Y, Christophersen B (1991) The effect of n-3 fatty acids on osmotic fragility of rat erythrocytes. Biochim Biophys Acta 1084: 251-254.

31. Dodge JT, Phillips GB (1967) Composition of phospholipids and of phospholipid fatty acids and aldehydes in human red cells. J Lipid Res 8: 667-675.

32. Renooij W, Van Golde LM, Zwaal RF, Van Deenen LL (1976) Topological asymmetry of phospholipid metabolism in rat erythrocyte membranes. Evidence for flip-flop of lecithin. Eur J Biochem 61: 53-58.
33. Kuypers FA, Easton EW, Van den Hoven R, Wensing T, Roelofsen B, et al. (1985) Survival of rabbit and horse erythrocytes in vivo after changing the fatty acyl composition of their phosphatidylcholine. Biochim Biophys Acta 819: 170-178.

34. Rawyler A, Van der Schaft PH, Roelofsen B, Op den Kamp JA (1985) Phospholipid localization in the plasma membrane of Friend erythroleukemic cells and mouse erythrocytes. Biochemistry 24: 1777-1783.

35. Van der Schaft PH, Beaumelle B, Vial H, Roelofsen B, Op den Kamp JA, et al. (1987) Phospholipid organization in monkey erythrocytes upon Plasmodium knowlesi infection. Biochim Biophys Acta 901: 1-14.

36. Virtanen JA, Cheng KH, Somerharju P (1998) Phospholipid composition of the mammalian red cell membrane can be rationalized by a superlattice model. Proc Natl Acad Sci USA 95: 4964-4969.

37. Boegheim Jr JP, Van Linde M, Op den Kamp JA, Roelofsen B (1983) The sphingomyelin pools in the outer and inner layer of the human erythrocyte membrane are composed of different molecular species. Biochim Biophys Acta 735: 438-442. 